Illinois State University

ISU ReD: Research and eData

Theses and Dissertations

3-17-2015

\title{
Mentoring: Experiences Of Physical Education Teachers With In- Content And Out-Of-Content Mentors
}

Molly Bosché Sharer

Illinois State University, mbshare@ilstu.edu

Follow this and additional works at: https://ir.library.illinoisstate.edu/etd

Part of the Other Education Commons

\section{Recommended Citation}

Sharer, Molly Bosché, "Mentoring: Experiences Of Physical Education Teachers With In-Content And OutOf-Content Mentors" (2015). Theses and Dissertations. 351.

https://ir.library.illinoisstate.edu/etd/351

This Thesis is brought to you for free and open access by ISU ReD: Research and eData. It has been accepted for inclusion in Theses and Dissertations by an authorized administrator of ISU ReD: Research and eData. For more information, please contact ISUReD@ilstu.edu. 


\title{
MENTORING: EXPERIENCES OF PHYSICAL EDUCATION TEACHERS WITH IN-CONTENT AND OUT-OF-CONTENT MENTORS
}

\author{
Molly Bosché Sharer
}

61 Pages

May 2015

This qualitative study investigates teachers' experiences with mentoring programs. An interpretive paradigm was used. Four one-hour long interviews were conducted, transcribed, and analyzed to examine mentoring experiences. Participants included one in-content mentoring pair (an early career physical education (PE) teacher and a veteran PE teacher) and one out-of-content pair (an early career PE teacher and a veteran kindergarten teacher). The research questions guiding this study were: What are the experiences of physical educators with mentors inside their content area? What are the experiences of physical educators with mentors outside their content area?

Findings showed that mentoring was an important support to provide early career PE teachers. Mentoring inside of teaching content had many benefits and mentoring outside of teaching content had challenges. Informal mentoring provided additional support for new teachers. A strong mentoring relationship depended on a quality mentor, compatible personalities, and frequent meeting opportunities for the pair. 
MENTORING: EXPERIENCES OF PHYSICAL EDUCATION TEACHERS WITH IN-CONTENT AND OUT-OF-CONTENT MENTORS

MOLLY BOSCHÉ SHARER

A Thesis Submitted in Partial Fulfillment of the Requirements for the Degree of

MASTER OF SCIENCE

School of Kinesiology and Recreation

ILLINOIS STATE UNIVERSITY

2015 
Copyright 2015 Molly Bosché Sharer 
MENTORING: EXPERIENCES OF PHYSICAL EDUCATION TEACHERS WITH IN-CONTENT AND OUT-OF-CONTENT MENTORS

\author{
MOLLY BOSCHÉ SHARER
}

COMMITTEE MEMBERS:

Deborah Garrahy, Chair

Amy Hurd

Margo Coleman

Mary Henninger 


\section{ACKNOWLEDGMENTS}

I would like to thank my committee members, Drs. Deborah Garrahy, Amy Hurd, Margo Coleman, and Mary Henninger for all of their time and guidance throughout the entire thesis process. Thank you to Dr. Wendy Troxel for offering advice and sharing helpful tips. Thank you to my parents, Marie Bosché and Randy Sharer for always offering encouragement and support. Thank you to my future husband, Chris Barbee, for his love, understanding, and cheerleading. Thank you to my coworkers, extended family, and friends for your listening ears. I could not have completed this thesis without your support.

M.B.S. 


\section{CONTENTS}

Page

ACKNOWLEDGMENTS

i

CONTENTS

TABLES

CHAPTER

I. INTRODUCTION 1

Purpose and Research Questions $\quad 2$

II. LITERATURE REVIEW 4

Introduction $\quad 4$

Mentoring $\quad 5$

Mentoring in Education $\quad 6$

Mentee Benefits

Mentor Benefits $\quad 7$

Quality Mentoring $\quad 8$

Informal vs Formal 9

Content Matching 10

Mentoring in Physical Education 12

Conclusion 14

Theoretical Framework $\quad 14$

$\begin{array}{ll}\text { III. } & \text { RESEARCH METHODOLOGY }\end{array}$

$\begin{array}{ll}\text { Research Paradigm } & 17\end{array}$

Positionality 18

Pilot Study 19

Research Methods $\quad 20$

Setting 20

Type of Study 20

Sampling 21

Participants $\quad 22$

Data collection $\quad 22$ 
Data Analysis 23

Ethical Issues $\quad 25$

Trustworthiness 25

Implications $\quad 26$

$\begin{array}{lll}\text { IV. RESULTS } & 28\end{array}$

$\begin{array}{ll}\text { Biographies } & 28\end{array}$

Joe $\quad 28$

Emily 28

Lisa $\quad 29$

Brad 29

Mentor Training $\quad 29$

Formal Mentoring 31

Benefits of In-Content Mentoring $\quad 33$

Informal Mentors $\quad 34$

Challenges With Out-of-Content Mentoring 36

Challenges With In-Content Mentoring 38

Benefits of Out-of-Content Mentoring 39

Benefits of Being a Mentor $\quad 40$

Mentoring Recommendations $\quad 41$

V. RECOMMENDATIONS AND CONCLUSIONS 43

$\begin{array}{ll}\text { REFERENCES } & 47\end{array}$

APPENDIX A: $\quad$ Recruitment Emails 54

$\begin{array}{ll}\text { APPENDIX B: } \quad \text { Informed Consent } & 57\end{array}$

APPENDIX C: $\quad$ Interview Questions 59 


\section{TABLES}

Table $\quad$ Page

1. Kram's Mentoring Functions 


\section{CHAPTER I}

\section{INTRODUCTION}

Teaching is a challenging profession, regardless of experience level. New educators face an overload of decisions and time consuming preparation. At times, beginning teachers find themselves in an environment very different than their teacherpreparation programs. When confronted with the choice to "go with the flow" or "fight for what's right," new teachers may feel overwhelmed. According to the Illinois State Board of Education (2012), nearly $40 \%$ of new teachers leave the profession within the first five years of their careers. Such turnover creates a revolving door effect, especially in hard-to-staff districts, which can be detrimental to student achievement (Ingersoll, 2012).

Researchers point to mentoring programs as a support and possible solution to this high drop-out rate. Formal mentoring programs pair veteran teachers with new educators to aid transition into the profession. Mentors serve as advisors with tasks such as answering questions, observing instruction, sharing resources, offering solutions, and, above all, listening. Mentoring has been found to decrease attrition rates of teachers (Smith \& Ingersoll, 2004).

Mentoring programs have been shown to save school districts money. Comprehensive induction for new teachers results in a return after five years of $\$ 1.66$ for each dollar invested (Villar \& Strong, 2007). Meanwhile, according to the Alliance for Excellent Education (2005), each teacher who leaves the profession in a mid-sized to 
large school district costs the district between $\$ 10,000$ to $\$ 18,000$ due to recruitment, hiring, and training costs.

The Illinois State Board of Education (2012) funds new teacher mentoring and induction programs as part of its grants for educator quality and support. The Illinois Induction Guide (Illinois State Board of Education, 2012) describes nine standards that must be met by these state funded programs: induction program leadership, program goals and design, resources, site administrator roles and responsibilities, mentor selection and assignment, mentor professional development, development of beginning teacher practice, formative assessment, and evaluation of induction programs.

Moving past generalities about mentoring programs, this research study focuses on mentoring within the content area of physical education. Physical education is considered a "special" course of study with unique pedagogical and environmental issues. What benefits and challenges are there to having an in-content and out-of-content mentor for new physical educators? A comparison of the experiences of a mentee with a physical educator as a mentor (in-content) to a mentee with a mentor who teaches a subject other than physical education (out-of-content) will be the focus of this study.

\section{Purpose and Research Questions}

Based upon my experiences and belief in the importance of mentoring, I became interested in learning more about the mentoring opportunities available to early career teachers. The National Commission of Teaching and America's Future (2003) estimates that one-third of all new teachers leave after three years, and $46 \%$ are gone within five years. Ingersoll (2002) found in the 1999-2000 school year, approximately 500,000 public and private school teachers left the teaching profession, with more than 123,000 
attributing their departure to a lack of appropriate administrative support. Nearly onefourth of new teachers leave the profession after only two years, and one-third leave after three years. Ingersoll recalculated these numbers in 2006 and they have not changed with any significance. As a fourth-year educator, these statistics are alarming and as a teacher of a "special" content area, I wish to focus on how these statistics affect physical educators specifically and how mentoring can change these numbers. Beginning physical educators struggle during induction (Williams \& Williamson, 1998) and could benefit from mentoring (Wright \& Smith, 2000). Millinger (2004) proposes formal mentoring programs, as part of a comprehensive professional development strategy, can help teachers meet the challenges of their profession. A gap exists in the literature when focusing on physical education. Additionally, absent from the conversation is the issue of the type of mentor that will best serve a new physical educator. According to Dodds (2005) little is known about how protégés describe their experiences of mentoring. This may be due to the fact that past research employed survey methodology to acquire information. This study will utilize a qualitative methodology to develop a better understanding of the experiences of new physical educators with mentors inside and outside their content area. The questions guiding this study are:

1. What are the experiences of physical educators with mentors inside their content?

2. What are the experiences of physical educators with mentors outside their content area? 


\section{CHAPTER II}

\section{LITERATURE REVIEW}

\section{Introduction}

Beginning teachers have many worries, including, but not limited to, their impact on student learning, class management, mechanics of teaching, etc. Napper-Owen and Philips (1995) explain these challenges play a prominent role in the high attrition rate of new teachers. Ingersoll (2003) found that $46 \%$ of all teachers in public schools will leave the profession within the first five years of teaching. These data refer to teachers from all disciplines including physical education. Assistance during induction seems to alleviate some of the stress and failure new teachers experience. Much has been written about the benefits of mentoring for new teachers. Huling and Resta (2001) describe four positive outcomes of the professional development tool of mentoring as professional competency, reflective practice, psychological benefits, and collaboration. Limited research has been conducted about the effects of mentoring in school subjects such as music, art, and physical education. In many schools, these content areas may only have one teacher in each of these specific content areas in the building. This is a serious dilemma given that Smith and Ingersoll (2004) found having a mentor in the same field is one of the strongest predictors of beginning teacher retention. This study will take the broad existing research about mentoring for beginning teachers and narrow the focus to mentoring for new physical educators. 


\section{Mentoring}

Starting a career can bring about feelings ranging from excitement to intimidation for a new professional. Pressure to successfully perform the tasks associated with a new job can be overwhelming in any profession. Organizations often provide induction activities to ease the transition of new employees. Many times, induction programs involve a mentoring component. According to one researcher:

A mentor is usually a senior, experienced employee who serves as a role model, provides support, direction, and feedback to the younger employee regarding career plans and interpersonal development, and increases the visibility of the protégé to decision-makers in the organization who may influence career opportunities. (Noe, 1988, p. 458)

Employers view mentoring as a way to support new workers but also see the benefit it can have on the organization itself. Joiner, Bartram, and Garreffa (2004) found that a successful mentoring program may be an important factor in positively influencing protégés' perceptions of career success and organizational commitment, which in turn is likely to reduce their turnover intentions. Lowering turnover rates saves an organization money by reducing training costs. Mentors serve to tell stories of how they coped with a particular situation, listen to mentees' concerns while helping them find their own way, and be generous with their time for meeting (Garvey, Alred, \& Smith, 1996). To reap these benefits, organizations need to provide quality mentors to their new employees. Tabbron, Mcaulay, and Cook (1997) explain an ideal mentor will be self-aware, have a commitment to personal development, and "bounce ideas around, offer a shoulder to cry on, let someone rant and rave, and think about the needs and longer-term future of their 
mentee" (p. 6). Much has been written about mentoring as a tool for employee induction. More specific research has been done exploring mentoring within the field of education.

\section{Mentoring in Education}

Teacher shortages and the staffing of schools are a growing concern in the United States. According to the Illinois State Board of Education (2012), nearly 40\% of new teachers leave the profession within the first five years of their careers. Often times, new teachers are given difficult assignments including teaching multiple subjects, developing curricula, and sponsoring school clubs or coaching sports. This pressure, mixed with a sense of isolation can leave a young professional feeling deflated. Ingersoll and Smith (2003) give voice to critics that view "teaching as an occupation that "cannibalizes its young' and in which the initiation of new teachers is akin to a sink or swim, trial by fire, or boot camp experience" (p. 28). It is when people are most vulnerable that they need support from trusted and qualified individuals. Danielson (2002) writes with good supervision from field-based teachers and university professors, "student teachers can begin to develop a deeper understanding of their work, but left to their own devices in the early years of teaching, they are unlikely to grow" (p. 183). Teacher mentoring has been suggested as an induction tool for new teachers. Nearly every state has a teacher mentoring policy, and many districts and schools provide their own additional mentoring programs (Rockoff, 2008). While these programs are seen as beneficial for teachers, schools can benefit as well. Smith and Ingersoll (2004) argue that school performance relies on adequate staffing with qualified teachers. Thus, "if induction programs do succeed in increasing the retention of beginning teachers, this could lead to a reduction in school staffing problems, which in turn could have a positive impact on school 
performance" (p. 685). On the topic of school improvement, Patton et al. (2005) explain the development of standards has shifted the focus to creating equal opportunities for students to learn and providing the best education to all children. To meet these standards, teachers need education, guidance, and support. Mentoring is a reform tool for improving schools by enhancing the quality of the teacher work force (Feiman-Nemser, 1996). Using mentoring as a reform tool may help sustain skillful teachers and foster a professional culture.

\section{Mentee Benefits}

Podsen and Denmark (2000) define teacher mentorship as "helping novices speed up the learning of a new job or skill and reduce the stress of transition, improving instructional performance of novices through modeling by a top performer, and socializing novices into the profession of teaching" (p. 31). Typical mentor support includes assistance in planning and delivering lessons, working with students with special needs, interacting with parents and staff, and providing encouragement (Ross, 1994).

\section{Mentor Benefits}

Participating as a mentor allows experienced teachers to impact the future of education by influencing the work of those new to the profession. Boreen, Jognson, Niday, and Potts (2000) found mentors often report continued contact with their protégés as this experience provides "their richest collegial interactions" (p. 3). Mentoring may prompt an experienced teacher to reflect on his or her practice. Danielson (2002) found the novice can "reawaken the veteran's questioning about practice, prompt a reexamination of certain teaching behaviors, and affirm the veteran teacher's own growth" (p. 184). Hawk (1986-87) studied 178 mentor teachers and found that more than two- 
thirds responded "definitely" to the statement that participation in the mentoring programs "provided positive professional growth" for them. When mentors were asked to elaborate on the ways they grew professionally, more than half did so with responses identifies in three categories: "(a) forced me to focus on and improve my own classroom teaching skills, (b) made me aware of the need for educators to communicate with each other, and (c) helped me better understand the principal and central office supervisors' roles" (p. 62).

Patton et al. (2005) note that mentors and mentees benefit and by sharing their experiences and "benefiting from personal support through mentoring and learning from each other, individuals developed new skills and insights that, for many, had a transformative impact on their own learning” (p. 320). Research has shown that mentoring is beneficial for both individuals involved (Gehrke \& Kay, 1984; Bona, Rinehart, \& Volbrecht, 1995).

\section{Quality Mentoring}

Ingersoll and Smith (2003) suggest that the most effective induction programs offer bundles or packages of supports and, in particular, "provide to beginning teachers a mentor from the same field and the opportunity to participate in group or collective planning and collaborative activities" (p. 38). Bower (2012) found an important psychosocial function of a mentor is "to act as a role model, by allowing the protégé to observe the behavior, attitudes, and values of the mentor" (p. 7). Rowley (1999) focused on six basic but essential qualities of a good mentor. These include: (1) being committed to the role of mentoring; (2) accepting of the beginning teacher; (3) skilled at providing instructional support; (4) effective in different interpersonal contexts; (5) model of 
continuous learning; and (6) knowledgeable in curriculum content and instructional strategies. While some researchers focus on mentor qualities, others explore a mentor's many roles. Schein (1978) submits that a mentor can serve as a: confidant, teacher, sponsor, role model, developer of talent, opener of doors, protector, and successful leader. Others would use these eight categories in future mentoring research. Gehrke and Kay (1984) interviewed 41 teachers and the most frequently filled roles were: teacher, confident, role model, developer of talents, and sponsor. Stroot et al. (1998) note that effective mentors possess rich and sophisticated content, curricular, and pedagogical knowledge and also have strong listening and communication skills that can support, motivate, and emotionally engage a protégé. For these qualities to be most beneficial, the mentor and mentee should be working within the same content.

\section{Informal vs Formal}

Formal mentoring is when a mentor is assigned by the school, district, or state; whereas informal mentors are people whom new teachers themselves choose to go to for help (Desimone et al., 2014). Formal mentoring should provide opportunities for dialogue, shared goal setting, mutual observation, and mutual reflection (Bell, 2007). The mentor and protégé should work together to document goals in areas needing improvement. The mentor should observe their mentee teaching and provide feedback during a mutual reflection time. It is thought that informal mentors focus more on social/emotional issues than formal mentors. DeWert, Babinski, and Jones (2003) found emotional support can "boost confidence of beginning teachers, increase their morale and job satisfaction, and reduce their feelings of isolation" (p. 319). Informal mentors might be colleagues, co-teachers, principals, other novice teachers, or school staff members. 
Gehrke and Kay (1984) suggest allowing novice and master more choice in the placement process to create a more valued relationship. For successful induction, informal mentoring should go hand-in-hand with formal mentoring. Desimone et al. (2014) suggest informal mentoring should be considered "explicitly as part of the 'constellation' or 'mosaic' of induction supports for new teachers and integrated to complement the role of formal mentors" (p. 102). Resources a formal mentor cannot provide might be found in a community of informal mentors, resulting in a well-rounded system of support for a novice teacher. Whether formal or informal, mentoring experiences should be local and contextually relevant (Ayers \& Griffin, 2005). It is difficult to reap the benefits of mentoring if interactions and communications are minimal. Rikard and Banville (2010) describe how one participant did not share an office with her mentor. They would meet once or twice per semester but rarely had time for a long discussion. She was fortunate to have an office mate who acted as a "surrogate mentor" with whom she interacted on a daily basis and had conversations about her teaching, planning, and classroom management. This example leads to the idea of having multiple mentors. Clark (2003) compares mentoring to the raising of children in that it "takes a village." Mentees may need different things from different people, depending on their expertise.

\section{Content Matching}

Successful mentor and novice matching can be a challenging task but is essential for a meaningful experience. Schwille, Nagel, and DeBolt (2000) suggest criteria used in determining mentor/novice matching might include complementary teaching assignments in level and academic discipline, opportunities for novices to work with different mentors 
who have varied strengths, compatible schedules that allow for frequent interaction, and ensuring mentor is located close to the novice's classroom. Ingersoll and Smith (2003) sampled 3,235 first year teachers from about the United States and found that the strongest factors for reducing turnover were "having a mentor from the same field, having common planning time with other teachers in the same subject, having regularly scheduled collaboration with other teachers, and being part of an external network of teachers" (p. 35). A match on content area expertise is related to the quality and outcomes of mentoring and is necessary for fostering productive interactions and teachers' instructional growth (Lopez, Lash, Schaffner, Shields, \& Wagner, 2004; Villar \& Strong, 2007). McCaughtry, Cothran, Kulinna, Martin, and Faust (2005) believe the importance of matching mentor and mentees' content depends on the purpose of the mentoring program. If the program in intended to have teacher mentors help their newer counterparts navigate school culture, classroom management, etc., then possession of rich and sophisticated content knowledge might not be essential for the mentor. On the other hand, "if the mentoring program is designed for the mentor to help the protégé learn to teach content better, implement newer technologies, or learn and implement new curriculum, then content knowledge might be extremely important for the mentor to possess" (p. 339). Consistent and sustained contact between mentor and protégé leads to a successful and effective mentoring program. Cothran et al. (2009) suggest that optimal mentoring occurs when "teachers involved in the same subject matter and/or grade level are assigned to work together" (p. 553). 


\section{Mentoring in Physical Education}

Ayers and Griffin (2005) use the metaphor of a mosaic for describing mentoring. A mosaic is a large picture or sculpture made up of smaller pieces like dots of color or bits of glass or tile. When you look closely, it is clear that each small component can stand alone, but when viewed as the larger whole, the mosaic portrays a more significant perspective than does each individual piece alone. Likewise, a single mentoring relationship can be meaningful on its own but the sum total of all mentoring relationships for each protégé represents a greater good.

Patton et al. (2005) used themes identified as facilitating mentoring relationships to conceptualize an empowerment model of mentoring. Researchers collected data from middle school physical education teachers who agreed to participate in the Assessment Initiative for Middle School Physical Education (AIMS-PE). Interview questions focused on how the mentoring system enabled teachers to examine their assessment practices and increase their students' knowledge and behaviors in physical activity. Results showed factors such as "like-minded people, reflection and improvement, and uniqueness of the mentoring relationship coupled with support, give and take, and trust created a synergy that empowered the individuals and their communities of practice" (p. 319).

The first teaching position for a physical educator often brings a "reality shock" in which they are caught between implementing what they learned during teacher preparation and on-the-job school expectations/norms (Lawson, 1989). The desire to conform to school practices may cause a "wash-out effect" that "overrides" the teacher preparation expectations. All new teachers face challenges; however, physical education teachers contend with special situations that need to be addressed by an induction 
program. For example, some teachers feel isolated in their building because they are the only teacher of that subject. They may also feel "physically isolated" being in a gymnasium, away from other classrooms.

Napper-Owen and Phillips (1995) conducted a case study on two beginning physical educators to investigate the impact of induction assistance. One resulting theme was "filling up my bag of tricks." The participant sought content ideas that were an appropriate level for students. An out-of-content mentor may find this type of need difficult to meet. Another theme was "learning to be more effective" in providing specific feedback to students. Rather than simply saying "Good job," the participant's mentor suggested focusing feedback on an element of the skill performance. Again, unless the mentor is familiar with physical education content, this type of assistance may not be provided.

Researchers found new teachers rushed lessons to get to playing games and they believed they were effective when student were "busy, happy, and good" (Placek, 1983). If a mentor is not familiar with quality physical education, they might believe this idea, too. Without continued support and companionship from peers who share the same educational philosophy, "the new teacher may be at risk of rejecting skills learned in the preparation program and reinforced during the induction year" (p. 326).

Williams and Williamson (1998) studied eight first-year physical educators to better understand social strategies they employed to succeed in the school environment. Strategic compliance was the most widely used social strategy. The authors explain, “Given the beginning teachers' experience, level of confidence, and position in a school, it is no surprise that these teachers chose the path of least resistance when dealing with 
conflicting professional principles" (p. 81). Participants gave examples of veteran teachers and principals persuading and encouraging them to go against appropriate teaching practices. This is a situation in which a quality mentor would be of great help and support for a novice teacher.

\section{Conclusion}

Danielson (2002) explains collegial relationships, fostered via formal and informal mentoring, "can initiate a deeper reflection about practice, offer encouragement that supports ongoing growth, and increase the job satisfaction needed for teachers to move through more mature career stages" (p. 185). McCaughtry et al. (2005) suggest that teachers who receive mentoring are "more likely to stay in teaching, be satisfied, hold better teaching attitudes, and implement more effective instructional practices and long term planning” (p. 328).

\section{Theoretical Framework}

Kram's (1988) theory of mentoring focuses on relationships in corporate organizations that enhance individuals' development in early, middle, and later career years. This theory is the result of research that began as a study of mentor relationships between junior and senior managers in one corporate setting and evolved into a program of research designed to clarify the nature of a variety of relationships between colleagues or peers who provide mentoring functions. Although developed in the context of corporate organizations, many researchers have transferred the theory to guide their work on mentoring in the field of education (Rikard \& Banville, 2010; Dodds, 2005; Bower, 2012; Gray, W. \& Gray, M., 1985; Ayers \& Griffin, 2005). Kram's theory of mentoring serves both career development and psychosocial functions, each subdivided into several 
categories, as shown in Table 1. Career development functions assist protégés in learning about organizational culture through sponsorship, coaching, protections, challenges, and exposure. Psychosocial functions increase protégés' efficacy, self-esteem, and selfconfidence through counseling, acceptance/conformation, role modeling, and friendship. Table 1

Kram's Mentoring Functions

\begin{tabular}{|c|c|}
\hline Career Functions & Psychosocial Functions \\
\hline Sponsorship & Role Modeling \\
\hline Exposure-and-Visibility & Counseling \\
\hline Coaching & Friendship \\
\hline Protection & \\
\hline Challenging Assignments & \\
\hline
\end{tabular}

Sponsorship involves actively nominating an individual for promotions. In the field of education, sponsorship might occur in formal or informal meetings with administrators. A mentor could recommend his or her mentee for a committee or task force. Exposureand-visibility is when a mentor takes an opportunity to demonstrate the competence and performance of the mentee. For example, a mentor could email the principal about a unique unit that their mentee developed for class. The mentoring function of coaching includes enhancing the mentee's pedagogical knowledge, teaching strategies, and understanding of how to navigate effectively the school context. Protection serves to shield the mentee from potentially damaging contact with administration or from unfair situations. A mentor may observe an inappropriate teaching practice during a mentee's lesson. The mentor can step in and explain the problem and give advice to the mentee before the new teacher is formally observed by an administrator. This action protects the mentee from a bad evaluation. Another example of protection would be when new 
teachers are asked to take on extra assignments, like coaching, and feel they are obligated to do so. A knowledgeable mentor can explain teachers' rights and protect them from making a stressful decision. When a mentor truly knows the protégé, he or she will provide challenging assignments to test the mentee's abilities and develop confidence. An important psychosocial function is role modeling. A mentor's attitudes, values, and behavior provide a model for the mentee to emulate. The period of career induction can be a stressful and emotional time. As a new teacher develops competence in the job, the mentor's acceptance-and-confirmation provides support and encouragement. The function of counseling allows a mentee to talk openly about anxieties and fears to his or her mentor, who acts as a sounding board and helps resolve problems. The function of friendship is characterized by social interaction that results in mutual liking and understanding. These informal exchanges can be work related or about outside work experiences. Kram's mentoring theory provided a framework for the research methodology, interview process, and data analysis used in this research study. 


\section{CHAPTER III}

\section{RESEARCH METHODOLOGY}

\section{Research Paradigm}

An interpretive research paradigm will guided this study. Researchers using the interpretive paradigm see themselves not merely as followers of scientific procedure but as interpreters and producers of it. For example, LeCompte, Preissle, and Tesch (1993) explain these studies are "framed by descriptions, explanations for, or meanings given to phenomena by both the research and the study participants rather that by the definitions and interpretations of the researcher alone" (pp. 31-32). This type of research assumes that reality is socially constructed. There is no single, observable reality in interpretivism; rather, there are multiple realities, or interpretations of a single event (Merriam, 2009). Researchers construct knowledge rather than "find" it. Ravitch and Riggan (2012) explain this type of research is viewed as an interpretive process: "the way we collect and analyze data is a process of making rather than discovering meaning" ( $\mathrm{p}$. 18). I studied how beginning physical educators described their experiences with mentoring. Participants' explanations of their experiences provided valuable knowledge to current understandings of mentoring. Using an interpretive paradigm, I gained greater knowledge of mentoring as a professional development support tool. The goal was to develop a better understanding of the range of mentoring experiences shared by the teachers and, based upon their experiences, I developed recommendations for mentoring practices. 


\section{Positionality}

I am a fourth-year physical education teacher. I started my career as a junior high school physical and health education teacher in a small school district enrolling 450 students. After two years, I lost my job due to a reduction in force at this school. I became a high school physical and health education teacher in a large school district $(13,600$ students $)$ and am in my second year of teaching in that district. As an undergraduate college student, I communicated frequently with professors during class, office hours, or through email and found that I learn better when I had the opportunity to work one-on-one with an instructor. The need for this type of support continued into my career. I was given a mentor in the small school outside my content area. She was a science teacher. I went to her with questions about technology, behavior management, evaluation, parental contact, school politics, teaching strategies, and much more. She observed my teaching and provided valuable feedback. She also provided emotional support during my first years of teaching. She had a way of reading my feelings and would "check-in" on me at just the right moments. Sometimes she would give advice or share a similar experience and other times she would just listen and validate my feelings.

She even invited me to dinner and events with her family because she knew I had moved out on my own and did not know many people. I can truly say my mentor helped me "survive" my first years of teaching.

When I transitioned to the larger school in a different district, I was provided a mentor within my department. Again, I go to her with questions about school policies, teaching strategies, behavior management, etc. Like my first mentor, she observes my teaching, but this experience is different than the first. This time, my mentor is able to 
give me content-specific feedback. She knows what quality instruction looks like in physical education and is able to provide pedagogical strategies that work in our specific setting. We are able to collaborate in a way that directly relates to physical education content. Upon reflection, I can say, however, my outside content mentor provided more social supports. For example, she introduced me to many teachers outside of physical education. Also, she was better able to refer me to people in school who could answer general education questions. My second mentor is so engrossed in the physical education setting that she cannot always answer questions about technology or general education practices. I have found strengths and challenges in both mentoring relationships. Because I have had mentors both inside and outside my content area, my positionality is more balanced and has allowed a broader understanding of the challenges of mentoring in and outside of content areas.

\section{Pilot Study}

A pilot study was conducted in order to refine interview protocols, questions, and coding schemes. Two participants were interviewed for the pilot study. The first participant was an elementary physical educator in a large school district that employs approximately 1,650 full-and part-time staff members to educate more than 13,600 students. She had experiences with mentors inside and outside of her content. The second participant was a high school physical educator in a small school district. He had experience with a mentor inside his content. These interviews were audiotaped, transcribed and lasted approximately 20 minutes in length.

The results of this pilot study indicated that sub questions or prompts should be added to interview questions to ensure participants fully describe the benefits and 
challenges of their mentoring experiences. Both participants in this pilot study mentioned having informal mentors. When their formal mentors were not available or did not have the information needed, new teachers found other teachers or staff members to reach out to. Informal mentors provided tips for the health classroom including technology information. Participants considered other new teachers to be informal mentors, often providing emotional support. These findings led me to add additional questions about informal mentoring. Results also led to an additional question about how mentoring affected new teachers' overall job satisfaction.

\section{Research Methods}

Setting. Four teachers agreed to participate in this study. All were selected from a large school district in the Midwest. The mentee participants were in their first five years of teaching. All participants were physical educators with at least half of their teaching schedule being in the physical education classroom. One mentoring pair worked at the primary level (kindergarten through fifth grades) and the other worked at the secondary level (sixth through eighth grades). One mentoring pair worked in the same content area (physical education) and the other worked in different content areas (physical education and kindergarten).

Type of study. This research was conducted as a phenomenological study. Schram (2003) explains phenomenology as a study of people's conscious experience of their life-world; that is, their "everyday life and social action" (p. 71). Merriam (2009) describes phenomenology as getting at the "essence or basic underlying structure of the meaning of an experience" (p. 25). The mentoring process that physical education teachers engage in should be studied this way because novice physical educators 
encounter some typical conflicts as they are socialized into their school environments. Stroot, Faucette, and Schwager (1993) explain the conflicts include reality shock, role conflict, isolation, and the wash-out effect. Physical educators work in a unique context, one in which they are usually alone, with few in-content colleagues and with many responsibilities. A phenomenological study is interested in the essence of a phenomenon; in this case, the unique experiences and challenges physical education teachers face during induction will be examined. This will also be case study research. Merriam (2009) describes qualitative case studies as ones in which researchers are the "primary instrument of data collection and analysis, an inductive investigative strategy, and the end product being richly descriptive" (p. 39). Miles, Huberman, and Saldaña (2014) think of the case as "a phenomenon of some sort occurring in a bounded context" (p. 28). They graphically present it as a circle with a heart in the center. The heart is the focus of the study, and the circle "defines the edge of the case: what will not be studied" (p. 29). In this study, I examined the process of mentoring.

Sampling. A purposive sampling was used in this study. These participants were selected because they met a specific criteria for the study. Merriam (2009) writes that "purposeful sampling is based on the assumption that the investigator wants to discover, understand, and gain insight and therefore must select a sample from which the most can be learned" (p. 77). Using purposive sampling, I identified and recruited two participants who have had mentors inside their content areas and two who have had mentors outside their content were recruited (See Appendix A). Once mentees agreed to participate, I obtained their mentors' contact information from the mentee. Once participants were identified and agreed to participate, a consent form was distributed and returned before 
beginning the study (See Appendix B). Interviews were conducted at locations and times of convenience to the participants.

Participants. The study involved interviewing two pairs of mentors-mentees for a total of four participants. The participants came from a Midwest school district that employs approximately 1,650 full-and part-time staff members to educate more than 13,600 students. The district consists of more than 214 square miles, with 16 elementary, four junior high schools, two high school buildings, one early learning center, and one vocational training site. The 2013-2014 operating budget was $\$ 149$ million. The mentee participants were in their first five years of teaching.

Data collection. Data were collected via interviews and artifacts. In person interviews were conducted with physical educators in their first five years in the profession. In person interviews also took place with the mentor teachers. A semistructured interview protocol was followed (See Appendix C). The interviews were conducted in the participant's location of choice, audio recorded, transcribed, and analyzed by the researcher.

Artifacts were collected including any mentoring materials provided to new teachers by their school districts. Requests were made to access any mentoring handouts, articles, and training materials received by the mentees. Logs of communication between mentees and their mentors such as journal entries, observation notes, emails, and contact logs were requested. Artifacts and interview transcripts will be analyzed.

Miles, Huberman, and Saldaña (2014) suggest using a data accounting log as a management method that "simply documents on a single form when and what types of data have been collected from specific participants and sites" (p. 122). This 
organizational tool allowed me to keep track of data and supplemental notes. I updated the data accounting log each time new data were collected.

A contact summary form was completed after each participant interview. The one-page document developed by Miles, Huberman, and Saldaña (2014) includes summarizing questions about a particular field contact. I reviewed notes and transcripts to develop an overall summary of the main points in the interview. This quick summary was helpful with future reflection and when analysis needed to be done.

\section{Data Analysis}

Based on Wolcott (1994), a three phase process for analysis was utilized. This system includes cycles of description, analysis, and interpretation of data. Coding strategies developed by Miles, Huberman, and Saldaña (2014) were used as a method of displaying the findings of this study. The first cycle involved provisional coding. According to Miles, Huberman, and Saldaña (2014), provisional coding begins with a "start list" of codes, "based on what preparatory investigation suggests might appear in the data before they are collected and analyzed" (p. 77). The following provisional codes were used: (a) career functions and (b) psychosocial functions. Career development functions assist protégés in learning about organizational culture through sponsorship, coaching, protections, challenge, and exposure. Psychosocial functions increase protégés' efficacy, self-esteem, and self-confidence through counseling, acceptance/confirmation, role modeling, and friendship (respect, support) (Kram, 1988).

The second cycle of coding involved patterned coding, which is a way of grouping initial summaries of data into a smaller number of categories, themes, or constructs. Pattern codes are explanatory or inferential codes, ones that identify an 
emergent theme, configuration, or explanation (Miles, Huberman, \& Saldaña, 2014). An analytic memo was written about overarching themes, causes or explanations, relationships between people, and connections to previous research. The analytic memos included my overall thoughts on analysis and what I think is "going on." Meetings were held electronically with a peer debriefer to guard against researcher bias throughout the data collection, analysis, and writing process. Lincoln and Guba (1985) describe this process as "exposing oneself to a disinterested peer in a manner paralleling an analytical sessions and for the purpose of exploring aspects of the inquiry that might otherwise remain only implicit within the inquirer's mind" (p. 308). The peer debriefer for this study was a professor who teaches graduate courses in research methods. This professor and I had never worked together, nor was she on my thesis committee. I electronically shared with her the participant transcripts. At the same time, I sent the second cycle coding document with initial summaries of each transcript. She provided feedback on overarching themes and coding methods. Later, I sent her the results section of this manuscript for review. She provided no corrections or changes.

An additional strategy I used to make sense of patterns from my codes was creating a matrix display. Developed by Miles, Huberman, and Saldaña (2014), the Conceptually Clustered Matrix: Organized by Themes will bring together "key data from key participants into a single matrix" (p. 178). This strategy helped me look "across" data and organize the associated themes. The tactic for generating meaning called factoring will also be employed. The method of factoring comes from "factor analysis, a statistical technique for representing a large number of measured variables in terms of a smaller number of hypothetical variables" (p. 286). Categories such as in-content 
mentors, formal mentors, informal mentors, and challenges with in-content mentors were identified and described using subcategories.

Mentoring materials were analyzed using tactics for testing or confirming findings by Miles, Huberman, and Saldaña (2014). The method of triangulation is "supposed to support a finding by showing that at least three independent measures of it agree with it or, at least, do not contradict it" (p. 299). Triangulation by data type, comparing qualitative text (mentoring program materials) and transcriptions of participant interviews were employed.

\section{Ethical Issues}

The research purpose and protocol were shared with participants prior to beginning the study. Participants decided if they were willing to participate in the study. To protect the confidentiality of all participants and the school district, pseudonyms were used in transcripts, data tables, and all reports. The audio records were kept on a password protected laptop and written transcriptions were kept in a locked file cabinet in my thesis committee advisor's office at Illinois State University.

Merriam (2009) discusses the issue of reciprocity by explaining that "most people who agree to be interviewed enjoy sharing their knowledge, opinions, or experiences" (p. 231). If the participants experienced a positive mentoring relationship, sharing their stories might be rewarding.

\section{Trustworthiness}

One potential threat to this study's trustworthiness is the participant-researcher relationship. The participants for this study were former classmates or colleagues of mine. They might have altered answers because of our connection. Glesne (2001) 
explains several validation techniques to increase the trustworthiness of research.

Triangulation is the use of "multiple data-collection methods, multiple sources, multiple investigators, and/or multiple theoretical perspectives" (Glesne, p. 49). Triangulation and use of multiple data-collection methods including interviews and document analysis were used in this study. Denzin (2001) made distinctions between triangulation by data source (which can include persons, times, places, etc.), by method (observation, interview document, by researcher (Investigator A, B, etc.), and by theory. Miles, Huberman, and Saldaña (2014) add data type (e.g., qualitative texts, audio/video recordings, quantitative data). Member checking was incorporated by returning interview transcripts to each participant to make sure their comments were accurately represented (See Appendix A). One participant emailed back with no necessary changes, two participants did not respond, and one called to ask if I had any questions about the answers given. I did not have questions, so no changes were made. Miles, Huberman, and Saldaña (2014) explain one of the most logical sources of corroboration is "the people you have talked with and watched" (p. 309). Participants can act as judges and evaluate the major findings of the study.

\section{Implications}

Analyzing mentoring experiences of new physical education teachers may lead to better understanding of their needs and a decrease in teacher attrition at district levels. By doing this, school districts and administrators can help decrease teacher attrition. Research within school subjects such as physical education suggest relatively high rates of attrition with 50\% from an Australian group of teachers (Macdonald, Hutchins \& Madden, 1994) and the expressed intention to leave by $80 \%$ of male and $40 \%$ of female 
physical educators in England (Evans \& Williams, 1988). Lawson (1983) noted that new physical education teachers frequently found their teaching situations different than the way they were described in teacher education programs and often responded in ways contradictory to their training. In response to problems facing beginning physical educators, researchers have called for active intervention for inductees into the teaching profession. Quality educators acting as mentors can guide new teachers through the sometimes difficult first years by providing advice, strategies, and a supportive listening ear. The narrative experiences shared by participants in the current research proposal will provide additional information to add to the growing body of literature related to mentoring new physical educators. 


\section{CHAPTER IV}

\section{RESULTS}

\section{Biographies}

Joe. Joe has been an educator for 31 years, teaching PE, health, and mathematics to students in grades six through twelve. The majority of his experience, 29 years, has been with middle school students at a central Illinois school. Joe has mentored new teachers informally and uncompensated for a long time. Formally, he has been paired with three to four physical educators in his school. He has worked with nearly 50 student teachers during his career. Joe was approached by a leader in the district about becoming a formal mentor. In this school district, formal mentoring includes a 2-hour training session in which administrators go over expectations. Joe was paid $\$ 330$ per year for participating in the formal mentoring program and has mentored Emily for two years.

Emily. Emily has been teaching for four years. She student taught at Joe's school under the supervision of another PE teacher and interacted with Joe frequently. After graduating from college, she substitute taught in central Illinois schools for a year, including a three-month maternity leave in a third grade classroom. Then, she taught junior high PE for two years in southern Illinois. After being riffed (reduction in force) from that position, she received an email from Joe about a job opening at his school. She applied for the job and was hired. She was in her second year of working at this Midwestern junior high, teaching health and PE. Emily was told Joe would be her mentor before the school year started and met him at the "new teacher orientation." 
Lisa. Lisa has been teaching for 17 years and started as a teacher's assistant in sixth grade and kindergarten. The teacher she was assisting changed grade levels and Lisa applied for her position. She taught first and third grade for two years and has been a kindergarten teacher for 15 years. Lisa is a Positive Behavior Intervention and Support (PBIS) coach in her school and has assumed leadership roles when building principals transitioned. Her building principal asked her to become a formal mentor for new teachers. Lisa has had five formal mentees in the last seven years, including three kindergarten/first grade pairings and two out of content pairings, including Brad. Lisa received $\$ 330$ per year for participating in the formal mentoring program.

Brad. Brad has been teaching for four years. He taught PE and health at a small junior high for one year. The next year he taught PE, health, and driver's education at the high school in the same district. The following year, he taught elementary PE at three schools in a Midwest school district and was mentored by Lisa. He was paired with his formal mentor during his third year by his principal.

\section{Mentor Training}

The Midwest school district had a formal program during the time the four participants were paired for mentoring. According to a 2013 memo from district officials to teacher union presidents, criteria for novice new teacher mentors were developed through a joint agreement with the union and was approved by the Illinois State Board of Education. The mentoring program was a component of the New Teacher Induction Program. This memo explained mentors must be tenured teachers, have three overall excellent evaluations, and complete the district mentoring class. Preference was given to mentors who participate in district level professional development, activities, and 
committees. Mentor responsibilities included participation in mentor training, 10 hours of contact time with mentee taking place outside of the regularly scheduled school day, four observations of mentee with prior observation meetings to discuss planning, completion of post observation forms providing mentee feedback, discussion of content area standards and professional development standards, and assisting mentee through coplanning, modeling of best practice use, and sharing of ideas, strategies, and resources. A similar memo from district officials to building administrators explained building administrators should match mentors with their newly hired teachers.

Mentors in the district received a stipend of $\$ 330$ after completing 10 contact hours and two observations with mentee during the year.

The two hour mentoring and induction program district training included a 31 slide PowerPoint Presentation. Topics of discussion included statistics on teacher attrition, what good mentors do and know, mentoring requirements, observation suggestions, mentoring strategies, and sample scenarios.

The district provided mentors and mentees with three forms to assist with observations. The first form was used prior to observation and allowed the mentee an opportunity to rehearse and describe the upcoming lesson. This could include purpose, content, and assessment. It could also include teacher expectations and instructional strategies. One section emphasized this is a non-evaluative process and writing on this document was not a requirement but is meant to stimulate discussion. The second form was an observation worksheet the mentor could use during the lesson. The nonevaluative form was used to provide written feedback to the mentee on observed classroom practices. The data collected was linked to the "Framework of Teaching," 
which was the framework in which official evaluations were linked. The third form was a post observation discussion form. The non-evaluative form provided an opportunity for the mentee to examine his/her own teaching with an open mind and to tentatively plan for the next lesson. The process should have been a collaborative effort between mentor and mentee.

\section{Formal Mentoring}

Emily and Brad's formal mentors provided them with career support. Emily explained Joe used his experience to provide advice. She quotes him in saying, "It isn't like this is what you have to do, but here is what I have experienced and here is what I know to work and here is what I know doesn't work, take it for what it is" (Emily, 2014, p. 8, line 284-285). She felt she could use the advice how she wanted. One mentoring method Emily described was role playing. She explained a situation to Joe that happened in her class and they talked through possible strategies. This helped her practice what to say and do before the real thing. Likewise, Brad and Lisa used this "scenario" method when he needed help with specific students. Lisa had many of Brad's students as kindergartners and was able to give advice about what teaching/behavior management strategies worked for each child.

Observations happened in two ways for Emily, Brad, and their mentors. Emily and Brad observed and were observed by their mentors. Emily said she gained a lot from observing Joe teach and interact with students. She observed Joe teach CPR, which was helpful when it came time for her to teach this in her Health class. She explained that what was most helpful was observing how Joe built relationships with students. She said 
he showed so much patience when working with students. This is a quality Joe saw in Emily as well.

Brad observed Lisa teaching and found it beneficial because he taught a lot of kindergarten classes. He found it helpful to watch her teaching strategies in the classroom and apply some of them in the gym. She taught him to, "Be tough with them, they'll know, and they'll reach that goal. Whatever you give them, they'll do, they'll reach up for it" (Brad, 2014, p. 2, lines 86-87). Lisa formally observed two of Brad's classes. She filled out an observation form created by the district and reviewed it with him afterward. He said he changed his discipline because of her feedback by becoming more strict with students. Sometime, meetings were informal. He would go into her room after school to talk or would talk with her after her students had PE.

Unlike Brad, Emily does not recall having any formal observations. She explained that because she and Joe taught in the same gymnasium and he had an office within earshot of her teaching space, Joe could observe her constantly. "He knows how things are going" (Emily, 2014, p. 5, line 169) due to proximity.

It is interesting to note that Emily never mentioned using or receiving the mentoring observation documents provided by the district. Joe said this put less pressure on Emily and allowed them to talk more freely. Emily went into detail about the affective mentoring that Joe provided her. She said he had the ability to "read her emotions" and often checked in with, "Are you OK" (Emily, 2014, p. 5, line 162)? When asked about this, Joe explained that often a conversation started with, "How was your evening? (Joe, 2014, p. 3, line 87)" and ended with information related to school and possible struggle spots. He said that frequent contact with his mentee helped him know 
her personally and professionally and helped him notice when something is wrong. Lisa believed too, that getting to know your mentee led to comfort in talking openly.

However, she and Brad reported they did not talk often about affective topics. Mainly, Brad explained Lisa helped him stay on top of things like calling parents and following through with punishments. Their mentoring focused on behavior and time management.

\section{Benefits of In-Content Mentoring}

Emily and Joe were both PE teachers and they believed this made their mentoring experience successful. When asked about having an in-content mentor/mentee, they both said that it made sense. Emily said it was somewhat helpful to talk with someone who had done what you are doing for much longer than you have, because they have gone through "the good, the bad, and the ugly, strengths and weaknesses" (Emily, 2014, p. 5, line 179). Joe said that the close proximity of their work environment allowed for less formal meetings and more consistent talking. He said he could offer a suggestion at the end of one hour and Emily could make a change for her next class period. This was possible because they saw each other in the gym and locker room area between each class.

Joe mentioned that he and Emily shared a conference period and this allowed for even more contact. Emily expressed concern that PE as a subject was neglected and, for this reason, new PE teachers should have PE teacher mentors because, hopefully, they take pride in the field. She proudly explained that Joe, two years away from retiring, was still working hard and this was great for her to see in her early years of teaching. "As long as they are doing their job as a mentor, in-house just makes sense given the nature of the subject," (Emily, 2014, p. 6, line 228) Emily said. 
Joe said teaching the same content as your mentee gave your advice validity and reliability. Your mentee knew you had been through the same issue in the same context and if you offered a suggestion, it had probably been proven to work. One example he offered mentees and student teachers was content specific. At the end of a PE lesson, the class is brought together for a closure to discuss what students learned. Unlike in a traditional classroom, students have freedom to move around the gym space. In his experience, students had stood behind him during closure and made rude gestures and caused distraction. He used his experience and suggested to his mentees they manage students' movement during closure so no one was behind them. He explained he could give Emily advice, she could watch it work in his class and, in a way, gained "experience" earlier because he could share what he had been through.

Lisa mentioned she mentored a new kindergarten teacher a few years ago and saw the benefit of having matching content. She felt more useful in this mentoring relationship because she knew issues that came up in her specific grade level and content. Also, her in-content mentee worked in the classroom next door and this proximity allowed for quick questions and more frequent observations.

\section{Informal Mentors}

Emily and Brad spoke about the informal mentors they have had during their careers. These were people, not assigned by the district, who supported them in various ways. Emily said the teachers in the PE department all acted as informal mentors for her. Each person provided something useful during her first years. Whether it was helping her with creating sub plans, discussing lesson ideas in her shared office, supporting her 
while she got her Master's degree, or just allowing her to observe their classes, other PE teachers served as informal mentors.

Emily explained that she did not have family in the community she taught in and the secretaries supported her in a "motherly way." Even the administrators in her building were hands off, but supportive. Emily was asked to teach health after she accepted the PE job. She had earned a minor in health during college but did not feel as confident in this content. She reached out to and was informally mentored by a health teacher from another junior high in the district.

There were two PE teachers at Brad's school, he and a woman named Jen. He and Jen would bounce ideas off each other and she would provide content-specific feedback that Lisa was unable to provide. Brad had gone to college with Jen so he felt comfortable asking her questions. They were able to work together on curriculum goals and shared new ideas with each other. Because she worked in the gym, students did not think twice when she observed Brad. As explained later, this was a problem for Lisa. Brad shared that having a coworker he enjoyed being around increased his job satisfaction.

Brad mentioned several other informal mentors including a PE teacher from another school in the district. Brad shared content materials with this teacher. Another informal mentor for Brad was a neighbor who was also a PE teacher. Brad could bounce ideas off of this neighbor. His cooperating teacher during student teaching "showed him the ropes" (Brad, 2014, p. 2, line 54). This informal mentor showed Brad how to treat and interact with students. Even now, Brad continues to send him questions through email and they get together for dinner occasionally. 
When it comes to coaching sports, Brad's brother was his mentor. He taught him “you have to have rules, be strict, but you have to have fun with kids or they aren't going to enjoy it" (Brad, 2014, p. 6, lines 260-261). Brad traveled between three schools when he worked with Lisa. He was mentored informally by a teacher at one of the schools and she taught him about the background of his students. Brad found this helpful as the demographics of the student population were different at each of the three schools he taught in. As you can see, Brad had many informal mentors and I argue this is because his formal mentor taught outside his content. He sought out and found the support he needed to be successful.

Lisa and Joe served as informal mentors to teachers. Lisa said the staff at her school saw her as a "mother" figure and a good listener and that her classroom was a place to vent. She said even veteran teachers came in and talked to her about family issues. Lisa enjoyed filling the role of informal mentor because she believed these relationships helped people make it through the day.

Joe mentored informally within the PE department mostly. He interacted with new coaches when they came to the gym area. He spoke with them about life and learned about their family and soon, he said, the conversation "evolves into issues he might be having in the classroom" (Joe, 2014, p. 9, line 294). He has helped young teachers, no matter their content, with classroom management.

\section{Challenges With Out-of-Content Mentoring}

Lisa and Brad taught different content and although they found the mentoring program beneficial, there were challenges because of this mixed match. Lisa was apprehensive about being paired with Brad and told him "I don't know how to do this. I 
don't know what you need because I don't know anything about PE. I don't know anything about your curriculum" (Lisa, 2014, p. 1, lines 34-35). Brad knew Lisa would be able to help him mostly with questions outside of PE content. One frustration Brad explained was the time it took to explain a PE scenario to a classroom teacher. There were environmental factors unique to teaching PE that other educators might not fully understand. For example, students are not restricted to sitting in a desk during PE and this freedom of movement can lead to behavior management issues not found in a classroom.

The next challenge described by Lisa and Brad was the physical proximity of workspace. Lisa's classroom was far away from Brad's gymnasium which made frequent observation impossible. Brad traveled between three schools during the day and Lisa found it difficult to keep track of his teaching schedule. During the year of Brad's mentoring, Lisa had eight students in her class with special needs and had a student teacher under her supervision. She found it difficult to leave her classroom for long while trying to meet the needs of her students and student teacher. Unlike Joe and Emily, Brad and Lisa had no common planning time which made it difficult to build a relationship. Lisa did make an effort to formally observe Brad's class on two occasions. But, as Brad described, "Students would see her come into observe and they would 'shape up"' (Brad, 2014, p. 5, line 223) so she never saw the authentic student behavior he reported. At the time, Lisa was filling in as an administrator and she concluded that students' behavior changed whenever she was present. Students were not used to seeing her in the gym and would be on their best behavior, especially if she had them in her class the year before. 
Brad acknowledged Lisa helped him with behavior management techniques. She had years of experience working with students and was on the behavior management committee at school. Although she was not an expert in the content of PE, she was able to help Brad with discipline techniques and he found this element of mentoring useful.

Although Joe had not mentored outside of his content, he shared some thoughts on the matter. He imagined that not seeing your mentor often would make observations feel more like an evaluation. It is important that mentees feel that their mentors are there to help, not judge. Also, if a mentor had never taught PE, Joe said, “They don't even know what it's like teaching 45 kids in PE because they only teach 20 in their classroom" (Joe, 2014, p. 10, lines 329-330). In that case, feedback might focus on classroom management. A veteran PE teacher would understand the environment of a gym, be able to move past the quantity of students and focus on the teaching strategies.

Joe also suggested some out-of-content mentors may believe in a negative stereotype of PE. If they had a bad experience in PE as a student, this might affect their ability to mentor a PE teacher. Interestingly, Emily saw this issue being more of a benefit than a challenge. She argued mentoring a PE teacher might change the out-of-content mentor's views about PE. They would see the changes made to PE content of the past and gain a better understanding of why PE is an invaluable subject matter.

\section{Challenges With In-Content Mentoring}

Joe and Emily mentioned a few potential challenges with mentoring within PE. Emily experienced positive and negative aspects of in-content mentoring. One of Emily's early mentors tended to be negative and would chose low effort lessons. This practice went against Emily's philosophy of teaching and put pressure on her to conform. 
In her first teaching position, Emily had a negative experience in her department. "As a new teacher people already think 'she isn't fantastic because she's new. She doesn't get it. She hasn't been through the hard times"' (Emily, 2014, p. 3, lines 88-90). Another coworker held a fitness only philosophy of PE, which was in conflict with Emily's comprehensive (fitness and skill development) philosophy.

Emily admitted that having a PE teacher as a mentor who did not care or was a bad example would be a difficult situation to be in as a new teacher. Joe agreed that it could be difficult for new teachers to have their voices heard and they might not want to rock the boat too much because administration would come to the PE department head about how new teachers were doing.

Experiencing a philosophical mismatch with the PE department puts pressure on an early career teacher. If that conflict extends to his or her mentor, the mentee might feel trapped. In extreme cases, this environment might lead the mentee to assimilate into teaching behaviors he or she knows are not best practice or might cause the mentee to drop out of the profession completely.

Emily discussed the idea of mentoring being an opportunity to change some attitudes about PE as a profession. When a mentoring pair both teach PE, they can celebrate teaching accomplishments but no one outside of PE hears about them. Having a teacher outside of PE mentor a quality young PE professional might improve the status of this content.

\section{Benefits of Out-of-Content Mentoring}

Emily described potential benefits to pairing PE teachers with mentors outside the content. She shared that PE teachers are very physically secluded in the school building. 
There are usually outside entrances by the PE offices and common areas like the staff mailroom are far from the gym. A PE teacher could enter the building by his or her office, teach in the gym, and exit the building without ever seeing another staff member outside of the PE department. Emily said having a mentor outside of PE might keep teachers informed on what is happening outside the PE area. It might allow PE teachers to see what students are like in a classroom setting. She believes it could help students if teachers shared information about what works in different content areas.

\section{Benefits of Being a Mentor}

Joe and Lisa expressed they gained as much from their mentees as they gave to them. Joe likened his relationship to a "two-way street," explaining his mentee brought a lot to the table that he might not have seen otherwise. He went on to say that being paired with a young professional allows veteran teachers to see new teaching concepts put into action. He provided the example of teambuilding. He first read of this idea of building community in a PE class through a variety of group challenges and trust activities in a professional journal. Seeing his mentee lead students through these activities at his school brought him a new level of understanding.

Lisa agreed, saying, "Getting to work with new, adamant teachers, rejuvenates and reenergizes you" (Lisa, 2014, p. 1, lines 24-25. She described the big picture by pointing out that "in order to get the school to work we have to go above and beyond" (Lisa, 2014, p. 5, lines 231-232). Mentoring is one way she goes the extra mile improve the whole school environment. 


\section{Mentoring Recommendations}

When asked to make a recommendation to the school district about mentoring, each participant had a similar response. Emily's recommendation was to pair early career PE teachers with high quality PE teacher mentors. She noted that simply having many years of experience is not enough, the mentors need to understand and demonstrate best practices in PE. She recommends "it needs to be a legit mentor who is there because they want to be a mentor, not because they need a body, but because they are going to be a support system for somebody and make new teachers better and hold them accountable as well” (Emily, 2014, p. 10, lines 364-366).

She said an interview with the mentee would provide a safe environment where he or she could explain how the mentoring relationship is going. The district needs to be willing to switch mentors and mentees until the right match is found. In addition to having an in-content mentor, Emily suggested the district provide opportunities for mentees to interact with informal mentors outside of their content. This would encourage discussion about student behavior plans, integrating other contents into PE, and help boost PE's image as a subject in school.

Brad's recommendation was similar to Emily's. He suggested the district provide new PE teachers with two mentors, one in-content and one out-of-content to "have the different worlds kind of coming together" (Brad, 2014, p. 7, line 309). He wishes the district would put more thought into finding a mentor for "exploratory" teachers (art, music, PE). He thinks it is important to match mentors and mentees by grade level. Joe said the ideal match up for a mentoring relationship is in content but he suggested supplementing with some unofficial out-of-content mentors. He likened this to 
the support provided to junior high students. Students are placed on a "team" during junior high, made up of four content teachers. Students travel together with the same group of kids between these four teachers. If a student is not doing well, the teachers are in close proximity to each other and have the opportunity to conference. They can brainstorm what the student might need and find the right supports to help. Likewise, providing a team of mentors for an early career teacher puts in place "preventative steps, safety nets there for the person" (Joe, 2014, p. 13, 438-439). Having access to mentors with differing strengths will increase the mentees' success.

Lisa recommended pairing mentors and mentees within the same content. She said she sees "the value of both, but I feel like the mentee, if it's out-of-content, they are shortchanged because I don't have enough time for them” (Lisa, 2014, p. 7, 306-307). 


\section{CHAPTER V \\ RECOMMENDATIONS AND CONCLUSIONS}

Following Kram's (1988) mentoring theory, mentoring has two functions: career (sponsorship, exposure-and-visibility, coaching, protection, challenging assignments) and psychosocial (role modeling, acceptance-and-confirmation, counseling, friendship). Participants in the current study identified the importance of addressing both types of needs.

Lisa and Brad found their mentoring relationship beneficial for some career needs. Mismatched contents areas, proximity of teaching space, and lack of "face-time" kept their relationship centered on career functions. Because psychosocial functions were not a focus, the potential outcome of their mentoring experience was not fully met.

Joe and Emily developed a meaningful friendship, having met earlier in their careers. Thanks to consistent "face-time," they were able to focus on psychosocial functions. This emphasis led to meaningful career mentoring. Joe and Emily's mentoring relationship illustrated a focus on both career and psychosocial aspects. This balance is a successful example of Kram's (1988) mentoring theory.

Several studies (Schwille, Nagel, \& DeBolt, 2000; Ingersoll \& Smith, 2003;

Lopez et al., 2004; Villar \& Strong, 2007; Cothran et al., 2009) have concluded matching mentoring pairs within the same content is beneficial. The current study presents perspectives from both inside and outside content mentoring experiences. Joe and Emily shared examples that demonstrate the benefit of having a mentor/mentee within the same 
content. These included providing/receiving advice based on past experience teaching PE, curricular and lesson guidance, and frequent "face time" based on proximity.

There are some universal teaching principles that mentors can advise a mentee on no matter their contents. Lisa and Brad focused on behavior management. Behavior management strategies used successfully in Lisa's kindergarten class also worked in the setting of PE. Although this was helpful, there were content-specific needs Brad had for which he had to seek out an informal mentor within his department.

Responses to the questions about informal mentors in the current study support the findings of previous research (Gehrke \& Kay, 1984; Desimone et al., 2014). Unique to this study, results showed a greater emphasis on the importance of informal mentors. Emily and Brad found emotional support from other staff members at their schools. Both emphasized the importance of having the opportunity to interact with informal mentors inside and outside of the PE department. Informal mentoring relationships provide teachers the chance to help students achieve. Strategies that work for students in one setting can be shared and used in another setting if teachers have a chance to communicate. Joe and Lisa saw the value in mentoring other teachers regardless of formality because communication between teachers was beneficial for school culture.

Based on previous research and data gathered in the current study, I believe mentoring is an important support to provide early career PE teachers. Mentoring inside of one's teaching content has many benefits (i.e. feedback specific to PE environment, office proximity, and experience with curriculum) while mentoring outside of teaching content has challenges (negative stereotype of PE, inexperience in gymnasium environment, and fewer opportunities for face-to-face meetings). Informal mentoring can 
provide additional support for new teachers (emotional guidance, technology development, individualized learning plans for shared students).

My conclusion is that a strong mentoring relationship depends on three variables: a quality mentor, compatible personalities, and frequent meeting opportunities for the pair. Previous research and the current study describe these variables.

Consistent with other findings (Garvey, Alred, \& Smith, 1996; Tabbron, Mcaulay, \& Cook, 1997), teachers in this study believed having a quality mentor served as a useful support for people just entering the workforce. A quality mentor is an expert in his or her content area and demonstrates best practices of teaching. Mentees tend to follow their mentors' examples of teaching and professional behavior. I recommend that school districts ask mentors to volunteer to ensure that their desire to support a new teacher is for the right reason: a professional experience that will benefit the mentor and the mentee. Joe mentored long before a formal mentoring program was developed in the district and would have continued to do so even without a stipend. He believed supporting new PE teachers enhanced the future of the profession. Additionally, Emily shared content knowledge with Joe. He had read about adventure education in journals but it was not until he saw Emily use this method of teaching that he believed in its value.

Along with matching content area and grade level, compatible personalities amongst the mentor and mentee are imperative. Within the first few months of the mentor/mentee assignment, district administrators should follow up with the mentor and mentee, perhaps through a survey instrument, to find out how the experience is going for both participants. If the feedback indicates similar concerns, district and building administrators should find an additional or new mentor for the mentee. 
Frequent meeting opportunities for the mentor and mentee to meet are imperative. District administrators should organize opportunities for mentees to interact with informal mentors. For example, planning a "meet and greet," "expert panel," or "social hour" would give mentees the chance to form meaningful relationships with coworkers in and outside of their content areas.

The phrase "It takes a village to raise a child" can be applied to teacher induction. A new teacher needs a content expert as a role model, a technology guru to ask questions, a confidante, and a school culture advisor to learn the "school norms." An early career teacher needs a community of people to support the transition from an undergraduate teacher candidate to a professional educator. If the district provides a strong support system, a new teacher is more likely to thrive during the first few years, have higher job satisfaction, and remain in the teaching profession. Pairing an early career PE teacher with a compatible, quality mentor and providing frequent meeting opportunities for the pair will foster a strong and successful mentoring relationship. 


\section{REFERENCES}

Alliance for Excellent Education. (2005). Teacher attrition: A costly loss to the nation and to the states. Washington, DC: Author.

American Association of State Colleges and Universities. (2006). Teacher induction programs: Trends and opportunities. Retrieved from http://www.aascu.org/uploadedFiles/AASCU/Content/Root/PolicyAndAdvocacy/ PolicyPublications/TeacherInduction.pdf

Ayers, S. F. \& Griffin, L. L. (2005). Chapter 5: PETE mentoring as a mosaic. Journal of Teaching in Physical Education, 24(4), 368-378.

Bell, D. L. (2007). A mentoring process to support teachers' growth and retention. Academic Leadership, 5(3), 7-11.

Bona, M. J., Rinehart, J., \& Volbrecht, R. M. (1995). Show me how to do like you: Comentoring as feminist pedagogy. Feminist Teacher, 9, 116-124

Boreen, J., Johnson, M. K., Niday, D., \& Potts, J. (2000). Mentoring beginning teachers: Guiding, reflecting, coaching. York, ME: Stenhouse Publishers.

Bower, G. G. (2012). Gender and mentoring. Journal of Physical Education, Recreation \& Dance, 83(2), 6-12.

Clark, J. E. (2003). The changing role of mentoring the future professorate with special attention to being a low-consensus discipline. Quest, 55(1), 51-61. 
Cothran, D., McCaughtry, N., Faust, R., Garn, A., Kulinna, P. H., \& Martin, J. (2009). Ementoring in physical education. Research Quarterly for Exercise and Sport, $80(3), 552-562$.

Danielson, L. (2002). Developing and retaining quality classroom teachers through mentoring. Clearing House, 75(4), 183-185.

Denzin, N. K. (2001). Interpretive interactionism (2nd ed.). Thousand Oaks, CA: Sage.

Desimone, L. M., Hochberg, E. D., Porter, A. C., Polikoff, M .S., Schwartz, R., \& Johnson, L. J. (2014). Formal and informal mentoring: Complementary, compensatory, or consistent? Journal of Teacher Education, 65(2), 88-110.

DeWert, M. H., Babinski, L. M., \& Jones, B. D. (2003). Safe passages: Providing online support to beginning teachers. Journal of Teacher Education, 54(4), 311-320.

Dodds, P. (2005). Chapter 4: PETE women's experiences of being mentored into postsecondary faculty positions. Journal of Teaching in Physical Education, 24(4), 344-367.

Evans, J., \& Williams, T. (1988). Moving up and getting out: The classes, gendered career opportunities of physical education teachers. In T. Templin, \& P. Schempp, Socialization in physical education: Learning to teach (pp. 235-249). Indianapolis: Benchmark Press.

Feiman-Namser, S. (1996). Teachers mentoring: A critical review. ERIC Digest. Washington, DC: ERIC Clearinghouse of Teaching and Teacher Education, (ERIC Document Reproduction Service No. ED397060).

Garvey, B., Alred, G., \& Smith, R. (1996). First-person mentoring. Career Development, $1(5), 10-14$.

Gehrke, N. J. \& Kay, R. S. (1984). The socialization of beginning teachers through mentor-protégé relationships. Journal of Teacher Education, 35(3), 21-24. 
Glesne, C. (2011). Becoming qualitative researchers. Boston, MA: Person Education, Inc. Gray, W. A. \& Gray, M. M. (1985). Educational leadership. Association for Supervision \& Curriculum Development, 43(3), 37-43.

Hawk, P. (1986-87). Beginning teacher programs: Benefits for the experienced educator in recruiting and inducting quality personnel for schools. Action in Teacher Education, 8(4), 59-63.

Huling-Austin, L. (1990). Teacher induction programs and internships. In W. R. Houston (Ed.), Handbook of research on teacher education (pp. 535-548). Reston, VA: Association of Teacher Educators.

Huling, L. \& Resta, V. (2001). Teacher mentoring as professional development. ERIC Digest. (ED460125)

Illinois State Board of Education. (2012). Illinois induction guide. Retrieved from http://intc.education.illinois.edu/guide/home

Illinois State Board of Education. (2012). Induction \& mentoring: Fact sheet. Retrieved from http://intc.education.illinois.edu/fact-sheet

Ingersoll, R. M. (2002). The teacher shortage: A case of wrong diagnosis and wrong prescription. NASSP Bulletin, 86, 16-31.

Ingersoll, R. (2003). Is there really a teacher shortage? Seattle: University of Washington, Center for the Study of Teaching and Policy.

Ingersoll, R. \& Smith, T. (2003). The wrong solution to the teacher shortage. Educational Leadership, 60(8), 30-33.

Ingersoll, R. (2012). Beginning teacher induction: What the data tell us. Phi Delta Kappan, 93(8), 47-51. 
Joiner, T. A., Bartram, T., \& Garreffaa, T. (2004). The effects of mentoring on perceived career success, commitment and turnover intentions. Journal of American Academy of Business, 5(1/2), 164-170.

Kram, K. E. (1988). Mentoring at work. Lanham, MD: University Press of America, Inc. Lawson, H. A. (1983). Toward a model of teacher socialization in physical education: The subjective warrant, recruitment, and teacher education. Journal of Teaching in Physical Education, 2(3), 3-16.

Lawson, H. A. (1989). From rookie to veteran: Workplace conditions in physical education and induction into the profession. In T.J. Templin \& P.G. Schempp (Eds.), Socialization into physical education: Learning to teach. (pp. 145-164). Indianapolis: Benchmark Press.

LeCompte, M. D., Preissle, J., Tesch, R. (1993). Ethnography and qualitative design in educational research. San Diego, CA: Academic Press.

Lincoln, Y. S. \& Guba, E. G. (1985). Naturalistic inquiry. Newbury Park, CA: Sage Publications.

Lopez, A., Lash, A., Schaffner, M., Shields, P., \& Wagner, M. (2004). Review of research on the impact of beginning teacher induction on teacher quality and retention. Menlo Park, CA: SRI International.

Macdonald, D., Hutchins, C., \& Madden, J. (1994). To leave or not to leave: Health and physical education teachers' career choices. The Australian Council for Health, Physical Education and Recreation Healthy Lifestyles Journal, 41(3), 19-23. 
McCaughtry, N., Cothran, D., Kulinna, P. H., Martin, J. J., \& Faust, R. (2005). Teachers mentoring teachers: A view over time. Journal of Teaching in Physical Education, 24(4), 326-343.

Merriam, S. B. (2009). Qualitative research: A guide to design and implementation. San Francisco, CA: Jossey-Bass.

Miles, M. B., Huberman, A. M., \& Saldaña. (2014). Qualitative data analysis: A methods sourcebook. Thousand Oaks, CA: SAGE Publications.

Millinger, C. S. (2004). Helping new teachers cope. Educational Leadership, 61(8), 6669.

Murnane, R., Singer, J., Willett, J., Kemple, J., Olsen, R. (Eds.). (1991). Who will teach?: Policies that matter. Cambridge, MA: Harvard University Press.

Napper-Owen, G., \& Phillips, A. (1995). A qualitative analysis of the impact of induction assistance on first-year physical educators. Journal of Teaching in Physical Education, 14, 305-327.

National Commission of Teaching and America's Future. (2003). No dream denied: A pledge to America's children: Summary report. Washington, DC.

Noe, R. A. (1988). An investigation of the determinants of successful assigned mentoring relationships. Personnel Psychology, 41, 457-479.

Patton, K., Griffin, L. L., Sheehy, D., Arnold, R., Gallo, A., Pagnano, K., Dodds, P., Henninger, M. L., \& James, A. (2005). Chapter 2: Navigating the mentoring process in a research-based teacher development project: A situated learning perspective. Journal of Teaching of Physical Education, 24(4), 302-325. 
Placek, J. (1983). Conceptions of success in teaching: Busy, happy, and good. Teaching in physical education, 46-56.

Podsen, I. J., \& Denmark, V. M. (2000). Coaching and mentoring first-year and student teachers. New York: Eye on Education.

Ravitch, S. M., \& Riggan, M. (2012). Reason \& rigor: How conceptual frameworks guide research. Thousand Oaks, CA: SAGE Publications.

Rikard, G. L. \& Banville, D. (2010). Effective mentoring: Critical to the professional development of first year physical educators. Journal of Teaching in Physical Education, 29, 245-261

Rockoff, J. E. (2008). Does mentoring reduce turnover and improve skills of new employees? Evidence from teachers in New York City (NBER Working Paper 13868). Cambridge, MA: National Bureau of Economic Research.

Ross, S. (1994). Perceptions of mentoring practices by interns and mentors in a professional development center. Ph.D. diss., University of South Dakota, Vermillion.

Rowley, J. B. (1999). The good mentor. Educational Leadership, 56(8), 20-22.

Schein, E. H. (1978). Socialization and learning to work. In Career dynamics: Matching individual and organizational needs. Reading, MA: Addison-Wesley.

Schram, T. H. (2003). Conceptualizing qualitative inquiry. Upper Saddle River, NJ: Prentice Hall.

Schwille, S. A., Nagel, A. L., \& DeBolt, G. P. (2000). Mentor selection and mentor/novice matching. Quality mentoring for novice teachers, 57-66. 
Smith, T., \& Ingersoll, R. (2004). Reducing teacher turnover: What are the components of effective induction? American Educational Research Journal, 41, 687-714.

Stroot, S. A., Faucette, N., \& Schwager, S. (1993). In the beginning: The induction of physical educators. Journal of Teaching in Physical Education, 12(4), 375-385.

Stroot, S., Keil, V., Stedman, P., Lohr, L., Faust, R., \& Schincariol-Randall, L. (1998). Peer assistance and review guidebook. Columbus, OH: Ohio Department of Education.

Tabbron, A., Macaulay, S., \& Cook, S. (1997). Making mentoring work. Training for Quality, 5(1), 6-9.

Villar, A., \& Strong, M. (2007). Is mentoring worth the money? A benefit-cost analysis and five-year rate of return of a comprehensive mentoring program for beginning teachers. ERS Spectrum, 25(3), 1-17.

Williams, J. A. \& Williamson, K. M. (1998). The socialization strategies of first-year physical education teachers: Conflict and concessions. Physical Educator, 55(2), $78-88$.

Wolcott, H. F. (1994). Transforming qualitative date: Description, analysis, and interpretation. Thousand Oaks, CA: SAGE Publications.

Wright, S. C. \& Smith, D. E. (2000). A case for formalized mentoring. Quest, 52(2), 200213. 


\section{APPENDIX A \\ RECRUITMENT EMAILS}

\section{Initial Email}

Email Subject: Physical Education Mentoring Study

I am writing to see if you would be interested in participating in my Master's thesis research study. Here is a little information about my study ... I am studying the mentoring experiences of PE teachers within their first 5 years of teaching and the experiences of their mentors. I am interested in the benefits and challenges of having a mentor/mentee. I will be interviewing 2 mentor-mentee pairs, one with matching content and one with differing contents. I am hoping to conduct an hour-long interview with each participant in early to mid-June. I am also hoping to gather any pertinent mentoring paperwork you have available (e.g. contact logs, observation notes, district mentoring materials and mentor-mentee communications).

Please let me know if you would be willing to participate in my study.

Thank you so much,

Molly, BS, MS Candidate

Faculty Advisors: Dr. Deborah Garrahy, Dr. Amy Hurd, Dr. Mary Henninger, and Dr. Margaret Coleman 


\section{Follow-Up Email}

Email Subject: Interview for Research Project

Thank you for agreeing to participate in my research study. I am writing to set a date for our interview about teacher mentoring. We can meet when and where ever you would like, I can come to your school or we can meet somewhere at ISU. The interview will take around an hour. I will send you the questions and consent form a week in advance of our meeting.

Thank you so much for helping with this project!

Sincerely,

Molly, BS, MS Candidate

Faculty Advisors: Dr. Deborah Garrahy, Dr. Amy Hurd, Dr. Mary Henninger, and Dr. Margaret Coleman 


\section{Transcript Email}

Email Subject: Interview Transcript

I want to thank you for helping with my thesis project. I appreciate you taking the time for our interview. I have finished transcribing and will begin analyzing all the data.

I have attached the transcript of our interview. I want to give you the opportunity to expand on your answers or make corrections/clarifications if you wish. If you prefer, I can bring you a hard copy. If you have changes, you can email them to me, I can make another recording, or I can pick them up.

Again, thank you for your continued support!

Sincerely,

Molly, BS, MS Candidate

Faculty Advisors: Dr. Deborah Garrahy, Dr. Amy Hurd, Dr. Mary Henninger, and Dr. Margaret Coleman 


\section{APPENDIX B}

\section{INFORMED CONSENT}

\section{ILLINOIS STATE UNIVERSITY}

\section{Mentoring: Experiences of physical education teacher with in-content and out-or- content mentors}

You have been invited to participate in a research study because you are in your first five years of teaching and are participating in a mentoring program or you are a mentor in this program. The purpose of this study is to better understand teachers' experiences with mentoring.

\section{Information}

I am a graduate student under the direction of Professor Garrahy in the School of Kinesiology \& Recreation at Illinois State University. I am conducting a research study to better understand new physical education teachers' experiences with mentoring programs. I am requesting your participation, which will involve approximately a one hour, audio recorded interview and collection of mentor/mentee documents provided by your school district.

\section{Risks}

While there are minimal risks involved in answering questions, it is always possible that while talking about mentoring experiences, emotional distress may occur. Participants can skip questions they do not wish to answer. There is a risk of social embarrassment because there are questions that ask the mentor to give feedback on areas of improvement by the mentee. Pseudonyms will be used in all research documents and audio recordings. Although small, there is still a risk of confidentiality loss.

\section{Benefits}

There are no immediate benefits to the participants. However, there may be an indirect benefit to sharing your experiences to further understanding about decreasing new teacher attrition rates.

\section{Confidentiality}

The information in the study will be kept confidential. Your information will be stored for two years and then all information will be destroyed. Data will be stored securely in a locked file cabinet or on a password-protected computer and will be made available only to the persons conducting this study. No reference that could link you to this study will be made in any oral or written reports. 
All interview recordings and transcripts will be kept confidential. Confidentiality will be insured through the assignment of a pseudonym - meaning your real name will never be used, nor any geographical location identified. Only the researchers will have access to your interview responses. After two years (December, 2016), the audio recording and transcript of your interview will be destroyed.

\section{Who to contact if you have questions about the study}

If you have questions at any time about the study or procedures, you may contact Dr. Deborah A. Garrahy at 56 DeGarmo Hall, Normal, IL 61790, at (309) 438-7054, or at dagarra@ilstu.edu. If you have any questions about your rights as a participant, you may contact the Research Ethics \& Compliance Office: (309) 438-2529 and/or rec@ilstu.edu.

\section{Voluntary Participation}

Your participation in this study is voluntary and you may withdraw at any time without penalty. Additionally, you may decline to respond to individual questions in the interview if you choose. If you choose to volunteer for this study, you may change your mind and withdraw your name at any time. If you withdraw from the study, your information will be destroyed immediately.

Participant's Signature:

Print Name:

Date: 


\section{APPENDIX C \\ INTERVIEW QUESTIONS}

\section{Interview Protocol (For mentees)}

Tell me a little bit about yourself, including your years of teaching, schools you've taught at, and what you teach.

What grade level(s) do you teach?

Do you teach at more than one school?

Do you teach more than one school subject (ex. Physical Education and Health?)

Let's talk about your job satisfaction. What would you say are the largest factors that have influenced your job satisfaction?

How satisfied are you with your job? Why so?

Mentoring? How so?

Please share with me your experiences with mentoring.

Formal vs. informal

In-content vs. out-of-content

How was mentor assigned

Career vs. affective functions

Are there benefits in having an in-content (out-of-content) mentor? If so, what are they?

Content-specific observations and feedback

Co-teaching

What challenges, if any, were there to having an in-content (out-of-content) mentor?

Please explain.

Co-teaching

Sharing gym space

What examples can you provide of feedback given to you by your mentor?

Did you have any "informal mentors?"

Who were they?

How did you find them?

What did they help you with?

What did you feel you did well at in your teaching?

Areas of possible improvement? 
What else would you like me to know about your mentoring experience? 


\section{Interview Protocol (For mentors)}

Tell me a little bit about yourself, including your years of teaching, schools you've taught at, and what you teach.

What grade level(s) do you teach?

Do you teach at more than one school?

Do you teach more than one school subject (ex. Physical Education and Health?)

Please explain how you became a mentor.

Duration

Number of mentees

Please share with me your experiences with mentoring.

Formal vs. informal

In-content vs. out-of-content

How was mentee assigned

Career vs. affective functions

Training

Compensation

Other

What are the benefits in having an in-content (out-of-content) mentee? Please explain.

Content-specific observations and feedback

Co-teaching

What are the challenges in having an in-content (out-of-content) mentee? Please explain.

Co-teaching

Sharing gym space

Can you give an example of some feedback you have given to your mentee?

Did you have any "informal mentees?"

Who were they?

How did you find them?

What did you help them with?

What do you feel your mentee does well at in their teaching?

Areas of possible improvement?

What else would you like me to know about your mentoring experience? 